\title{
A.A.Lebedenko, 0.E.Semernik \\ Neurohumoral aspects of bronchial asthma exacerbation in children
}

\begin{abstract}
Summary
The leading role in maintenance of bronchial smooth muscle tone belongs to central and peripheral neurohumoral regulatory mechanisms. Correction of the bronchial tone regulatory imbalance in children with asthma exacerbation could discover the optimal therapeutic approach. According to this, 82 patients with asthma exacerbation were examined; 30 healthy children were as controls. Autonomic neural system was investigated in all asthmatic children using spectrum analysis of the heart rhythm variability; vasoactive intestinal peptide (VIP), norepinephrine, cortisole and acetylcholine esterase were also measured in serum. In children with asthma, the prevalence of $2^{\text {nd }}$ order slow waves was found indicating enhanced humoral and metabolic effects; this fact was in consistence with increased serum VIP level in asthma patients $(110.61 \pm 11.89 \mathrm{ng} / \mathrm{ml}$ vs $53.26 \pm 16.08 \mathrm{ng} / \mathrm{ml}$ in controls). In $40 \%$ of children experiencing asthma attacks, a coefficient of vagosympathetic balance exceeded 2.0 indicating the sympathetic nervous system activation. In asthma patients, increased concentrations of norepinephrine $(688.78 \pm 63.35 \mathrm{pg} / \mathrm{ml} v \mathrm{vs} 416.00 \pm$ $21.26 \mathrm{pg} / \mathrm{ml}$ in controls; $p<0.05)$, acetylcholine esterase (7 897.28 $\pm 307.25 \mathrm{U} / \mathrm{L} v s 6662.38 \pm 180.83 \mathrm{U} / \mathrm{L} ; p<0.05)$, and cortisol (443.138 \pm $46.8839 \mathrm{nmol} / \mathrm{L}$ ) were also found. These features of the neurohumoral dysregulation could be used to improve bronchodilating therapy in asthmatic children.

Key words: bronchial asthma, children, spectrum analysis, neurohumoral regulation
\end{abstract}

\section{Резюме}

Ведущая роль в поддержании тонуса гладкой мускулатуры бронхов принадлежит центральным и периферическим звеньям нейрогуморального комплекса. Акцентуализация патогенетических звеньев дисбаланса регуляторных механизмов бронхиального тонуса у детей с обострением бронхиальной астмы (БА) позволит найти способы их устранения при оптимальном терапевтическом воздействии. Для реализации поставленной цели были обследованы 82 пациента в период обострения БА. Группу контроля составили 30 здоровых детей. Всем больным проведено комплексное исследование вегетативной нервной системы методом спектрального анализа вариабельности сердечного ритма, а также определение в сыворотке крови вазоинтестинального пептида, норадреналина, кортизола и ацетилхолинэстеразы. По данным спектрального анализа у детей в период обострения БА отмечалось преобладание медленных волн II порядка, свидетельствуюших о повышении гуморально-метаболических влияний. Доказательством этого является увеличение концентрации вазоинтестинального пептида в плазме крови пациентов с БА $(110,61 \pm 11,89$ нг / мл) по сравнению с контрольной группой $(53,26 \pm$ 16,08 нг / мл). Коэффициент вагосимпатического баланса у 40 \% детей, испытывающих приступ удушья, превышал 2,0, что свидетельствует об активации симпатического отдела вегетативной нервной системы. Необходимо также отметить, что у пациентов с БА по сравнению с группой контроля отмечалось повышение концентрации норадреналина в сыворотке крови $(688,78 \pm 63,35$ нг / мл vs 416,00 \pm $21,26$ нг / мл; $p<0,05)$, холинэстеразы (7 897,28 \pm 307,25 ммоль / л vs $6662,38 \pm 180,83$ ммоль / л; $p<0,05)$ и кортизола $(443,138 \pm$ 46,8839 нмоль / л). Выявленные особенности нейрогуморальной регуляции у больных БА позволяют оптимизировать бронхолитическую терапию в период обострения заболевания.

Ключевые слова: бронхиальная астма, дети, спектральный анализ, нейрогуморальная регуляция.

Проблема бронхиальной астмы (БА) у детей чрезвычайно актуальна. По данным эпидемиологических исследований, распространенность БА в детской популяции в России составляет 5,6-12,1 \% [1]. БА может явиться причиной инвалидизации детей, а тяжелое обострение болезни может представлять определенную угрозу для их жизни. В основе развития приступа удушья при БА лежат различные механизмы как обратимого (бронхоспазм, воспалительный отек слизистой оболочки и подслизистого слоя бронхиальной стенки, гиперсекреция вязкой слизи и мукоцилиарная недостаточность), так и необратимого характера [2, 3]. При этом значительная роль в патогенезе бронхообструкции принадлежит изменениям не только вегетативной нервной системы (ВНС), но и нейрогуморального звена регуляции тонуса бронхов. В последние годы существенно расширились представления о регуляции тонуса гладкой мускулатуры бронхов как в норме, так и при патологии дыхательной системы. Наряду с нейрогенными воздействиями, представленными холинергической регуляцией, связанной прежде всего с активностью блуждающего нерва и различными типами холинергических рецепторов, и адренергическими механизмами, реализующимися на уровне адренорецепторов, циклических нуклеотидов, ионов кальция, доказана важная роль в функционировании бронхолегочного аппарата нехолинергических неадренергических механизмов (НАНХ) и разнообразных факторов нейрогуморальной природы [4-6]. Поэтому 
изучение изменений, происходящих в организме ребенка в период обострения БА, позволит найти ключ к дальнейшему пониманию процессов бронхообструкции и расширить терапевтические возможности ее купирования.

Целью исследования явилось изучение нейрогуморальных аспектов обострения БА у детей.

\section{Материалы и методы}

Для реализации поставленной цели были обследованы дети $(n=82)$ с установленным диагнозом БА. Средний возраст больных составил 12,2 \pm 3,5 года. Среди пациентов преобладали мальчики - 58 $(70,73 \%)$, девочек было 24 (29,27 \%). Верификация диагноза проводилась в соответствии с Национальной программой "Бронхиальная астма у детей. Стратегия лечения и профилактика" (2012) [7]. Группу контроля $(n=30)$ составили дети, возраст и пол которых были сопоставимы. Критерии включения в исследование были следующими: диагноз БА, установленный за $\leq 6$ мес. до начала исследования; на момент поступления у всех больных отмечался приступ БА легкой степени (наличие симптомов бронхиальной обструкции в виде одышки, приступообразного кашля; объем форсированного выдоха за 1-ю секунду $>80 \%$ от должных значений; прирост пиковой скорости выдоха (ПСВ) по данным пикфлоуметрии после ингаляции бронхолитика > $12 \%$ ). Критерии исключения: тяжелое обострение БА, требующее применения системных глюкокортикостероидов; повышенная чувствительность к одному из препаратов; сопутствующие заболевания сердечнососудистой системы.

При поступлении всем детям до начала ингаляционной терапии был произведен забор крови для определения уровня вазоинтестинального пептида (ВИП), норадреналина (НА), кортизола, ацетилхолинэстеразы (АХЭ) в плазме и сыворотке крови.

Изучение исходного вегетативного тонуса у детей с БА проводилось по таблицам A.M.Вейна [8], а также методом кардиоинтервалографии с использованием спектрального анализа вариабельности сердечного ритма [9] с помощью кардиоанализатора "АНКАР131" ("Медиком МТД", Таганрог). У всех пациентов методом эхокардиографии были определены изменения кардиогемодинамических показателей на фоне применения бронхолитических препаратов (фенотерол, ипратропиума бромид и комбинированный препарат фенотерол + ипратропиума бромид). Лекарственные препараты доставлялись в верхние дыхательные пути в форме аэрозоля с помощью компрессорных небулайзеров (Omron CompAir NE-C28-E) в дозах, рекомендованных для данного возраста и степени тяжести приступа БА (15-20 капель лекарственных веществ были разведены изотоническим раствором хлорида натрия до объема 2 мл, ингаляция длилась $\approx 10$ мин) [7].

Статистическая обработка результатов исследования проводилась с помощью набора прикладных программ Microsoft Office 2000 Pro for Windows OSR 2 на ЭВМ PC Intel Pentium 166 (Microsoft Office 97 Professional, 1997), для статистического анализа применялась компьютерная программа Statistica 6.0. В анализ было включено определение средних арифметических величин, коэффициентов корреляции. Достоверность различий между группами по среднеарифметическим величинам, а также достоверность коэффициента корреляции определялась по критерию Стьюдента $(t)$. Достоверным считался результат при $t>2$, при котором $p<0,05$ [10].

\section{Результаты}

У подавляющего большинства обследованных детей с БА в период обострения результаты спектрального анализа вариабельности сердечного ритма свидетельствовали об увеличении активности симпатического отдела ВНС. Так, у 79 (96,34 \%) пациентов значение спектральной мощности медленных волн превышало $40 \%$, а среднее значение коэффициента вагосимпатического баланса составило 2,158 \pm 0,282, что также указывает на централизацию управления процессами регуляции бронхиального тонуса и смещение его в сторону преобладания активности симпатического отдела ВНС.

Полученные результаты исследования нейрогуморального звена у детей с обострением БА подтверждают данное высказывание, т. к. средние значения уровня НА в сыворотке крови в период приступа составили 688,786 \pm 63,352 пг / мл, что достоверно превышает показатели у пациентов контрольной группы $-416,0000 \pm 21,2558$ пг / мл $(p=0,041)$ (см. таблицу). Известно, что именно НА является главным медиатором симпатической активности в легких, оказывающим непосредственное действие на $\beta_{2}$-адренорецепторы, расположенные на мембранах гладких мышечных волокон бронхов, приводя к их расширению. Следовательно, можно предположить, что мобилизация защитных сил организма ребенка в острый период заболевания в виде выброса дополнительного количества нейромедиаторов из пресинаптической мембраны симпатических нервов способствует более быстрому купированию бронхоспазма. Однако не стоит забывать, что эффективность данного процесса во многом определяется активностью, специфичностью, а также количеством свободных $\beta_{2}$-адренорецепторов, локализующихся на постсинаптической мембране.

Главным эндогенным глюкокортикостероидом, способствующим увеличению экспрессии адренорецепторов на постсинаптической мембране, является кортизол. Недостаточный выброс его клубочковой зоной надпочечников приводит к значительным нарушениям процессов регуляции бронхиального тонуса. В результате исследования показано, что среднее значение уровня кортизола в сыворотке крови детей с БА достоверно отличается от такового у пациентов контрольной группы ( $p=0,048)$ и составляет 443,1380 \pm 46,8839 нмоль / л (см. таблицу). Повышение уровня эндогенного глюкокортикостероида свидетельствует о мобилизации защитных резервов 
Лебеденко A.A., Семерник O.E. Нейрогуморальные аспекты обострения бронхиальной астмы у детей

Таблица

Концентрация биологически активных веществ у детей с БА и здоровых пациентов

\begin{tabular}{|l|c|c|c|}
\hline \multicolumn{1}{|c|}{ Биологически активное вещество } & Дети с БА & Контрольная группа & $p$ \\
\hline ВИП, нмоль / л & $110,6040 \pm 11,8851$ & $53,2590 \pm 16,0802$ & 0,016 \\
\hline НА, пг / мл & $688,7860 \pm 63,3522$ & $416,0000 \pm 21,2558$ & 0,041 \\
\hline АХЭ, Ед. / & $7897,2760 \pm 307,2456$ & $6662,3750 \pm 180,8252$ & 0,046 \\
\hline Кортизол, нмоль / л & $443,1380 \pm 46,8839$ & $289,857 \pm 53,674$ & 0,048 \\
\hline
\end{tabular}

организма - активации гипоталамо-гипофизарнонадпочечниковой системы, способствующей более быстрому купированию бронхоспазма. Кортизол способен непосредственно или опосредованно модулировать сократительную способность гладкой мускулатуры дыхательных путей, предотвращая повышение внутриклеточной концентрации ионов кальция или уменьшая количество М2- и М3-холинорецепторов, а также способствует расслаблению гладкой мускулатуры, усиливая активацию механизма, зависимого от циклического аденозинмонофосфата (цАМФ) (повышение экспрессии $\beta$-рецепторов, восстановление их чувствительности через повышение активности аденилатциклазы и цАМФзависимой протеинкиназы), или цАМФ-независимых механизмов (активация натрий-калиевого насоса). Кроме того, он обладает пермиссионным действием на синтез катехоламинов, повышая активность фермента фенилэтаноламин-N-метилтрансферазы в мозговом веществе надпочечников, оказывает антипролиферативный эффект на гладкомышечные клетки [11]. Однако необходимо отметить, что концентрация кортизола как у пациентов с БА, так и детей контрольной группы не превышала нормальных значений.

Относительное повышение уровня кортизола в сыворотке крови у больных БА согласуется с увеличением у этих пациентов в спектрограмме медленноволновых составляющих ритма. Дополнительное экзогенное введение $\beta_{2}$-адреномиметиков на фоне активации эндогенных механизмов способствует более быстрому купированию бронхообструкции. Однако необходимо учитывать, что значительное увеличение количества веществ, активирующих адренорецепторы, может оказать негативное влияние на здоровье ребенка, поэтому терапию конкретному больному необходимо подбирать, соизмеряя ее со степенью активности симпатической нервной системы, причем наиболее информативным в данном отношении является индекс вагосимпатического взаимодействия. По результатам проведенных исследований у большинства детей с БА, имеющих значения коэффициента вагосимпатического балан$\mathrm{ca}(\mathrm{LF} / \mathrm{HF})>2,0$, отмечается повышение уровня катехоламинов $(54,55 \%)$ и кортизола $(54,55 \%)$ в сыворотке крови. Применение у пациентов $(n=45)$ с выраженной симпатикотонией (LF / HF > 3,0) препаратов, содержащих адреномиметик (фенотерол или комбинированный препарат фенотерол + ипратропиума бромид), привело к достоверно значимым увеличениям показателей ПСВ $(p<0,05)$, од- нако сопровождалось значительными изменениями со стороны кардиогемодинамики. Так, у детей, получивших фенотерол, регистрировалось повышение давления на клапанах легочной артерии на > 36,9 \%; показатели скорости кровотока в систолу на митральном клапане возросли на 11,3\%, при этом отмечалось снижение отношения максимальных скоростей транстрикуспидального потока в фазы раннего диастолического наполнения правого желудочка и систолы правого предсердия (Е / А) на трикуспидальном клапане. В группе детей, получавших комбинированный препарат фенотерол + ипратропиума бромид, столь выраженных изменений не отмечено: показатели давления на клапанах легочной артерии возросли лишь на 6,6 \%; скорость кровотока в митральном клапане - на 5,3\%, а при оценке параметров, отражающих работу правых отделов сердца, отмечалась нормализация Е / А на трикуспидальном клапане. Существенному снижению риска нежелательных эффектов со стороны сердечно-сосудистой системы способствует в 2 раза меньшая дозировка $\beta_{2}$-агониста в составе комбинированного препарата (1 мл - 500 мкг фенотерола и 250 мкг ипратропиума бромида) по сравнению с монопрепаратом фенотеролом (1 мл - 1000 мкг фенотерола).

Необходимо отметить, что у 48,78 \% обследованных пациентов процентное значение HF-волн, свидетельствующих об активации блуждающего нерва, превышало нормальные значения. Данные изменения объяснимы с точки зрения патогенеза БА: бронхоспастическая реакция, обусловленная раздражением нервных волокон, опосредуется выделением ацетилхолина в окончаниях постганглионарных нервных волокон. Однако при сохранении метаболической функции легких происходит дополнительный выброс АХЭ в межсинаптическое пространство, следовательно, уменьшение уровня ацетилхолина. У обследованных детей было констатировано увеличение уровня АХЭ в сыворотке крови по сравнению со здоровыми пациентами ( $p=0,046)$ (см. таблицу). Возможно, это связано с тем, что для активности АХЭ характерны фазные изменения, поэтому сохраняющееся повышение активности парасимпатического отдела ВНС, по данным спектрального анализа у 17,07 \% обследованных, диктует необходимость добавления в план терапии антихолинергических препаратов. Поэтому пациентам с обострением БА $(n=25)$ и ваготонией был назначен ипратропиума бромид. В результате отмечено достоверное увеличение показателей ПСВ $(p<0,05)$, сопровождающееся повышением значения коэффициента вагосимпати- 
ческого баланса и снижением процентного содержания в спектрограмме HF-волн: до ингаляции $63,65 \pm 18,84 \%$, после - 50,95 $\pm 26,93 \%$. Важно отметить, что в этой группе пациентов выявлено повышение давления на клапанах легочной артерии на $<10,8 \%$, а у показателей скорости и давления на митральный клапан в систолу желудочков не имелось достоверных различий до и после ингаляции $(p>0,05)$, причем зарегистрирована нормализация показателя Е / А на трикуспидальном клапане у 7,14 \% больных.

По результатам спектрального анализа вариабельности сердечного ритма у 63,41 \% детей, страдающих БА, значения мощности медленных волн II порядка (VLF-волн) превышали нормальные значения, при этом 52,43 \% пациентов имели доминирование в спектрограмме VLF-волн, что свидетельствует об активации нейрогуморальных каналов регуляции витальных функций в организме ребенка, таких, например, как НАНХ. Доказательством этому служит значительное увеличение концентрации главного нейромедиатора, обладающего мощным бронходилатирующим действием - ВИП, в > 2 раза превышающей таковые значения у пациентов контрольной группы (см. таблицу). При этом необходимо отметить, что чем выше значения спектральной мощности VLF-волн регистрировались у больного, тем более высоким был уровень ВИП в плазме крови пациента.

\section{Заключение}

В патогенезе БА значительную роль играют нейрорецепторные взаимодействия медиаторов симпатической, парасимпатической и НАНХ-систем. Сбалансированные в норме комплексные пути нейрогуморальной регуляции, обеспечивающие оптимальный уровень тонуса бронхов, значительно изменяются в условиях патологии. Определение процентного распределения волн в спектрограмме при кардиоинтервалографии, а также изменений концентраций биологически активных веществ в крови ребенка с БА позволяют выявить степень дисбаланса нейрорегулирующих систем в генезе бронхиальной обструкции. Глубокое понимание патогенетических механизмов и изменений, происхо- дящих в вегетативном статусе ребенка, помогает не только разобраться в причинах развития бронхообструкции, но и подобрать бронхолитический препарат с учетом его индивидуальных особенностей.

\section{Литература}

1. Балаболкин И.И., Булгакова В.А. (ред.). Клиническая аллергология детского возраста с неотложными состояниями: Руководство для врачей. М.: МИА; 2011.

2. Зайцева С.В., Муртазаева О.А. Синдром бронхиальной обструкции у детей. Трудный пациент 2012; 10 (2-3): 34-39.

3. Stiefelhagen $P$. Pathogenesis, diagnosis and therapy of bronchial asthma. How can the lungs be freed? MMW Fortschr. Med. 2011; 153 (4): 12-14.

4. Surov A., Landyshev Iu. S., Lazutkina E. L. et al. The role of non-adrenergic non-cholinergic nervous system in pathogenesis of bronchial asthma. Ter. Arkh. 2008; 80 (3): 90-95.

5. Pisi G., Olivieri D., Chetta A. The airway neurogenic inflammation: clinical and pharmacological implications. Inflamm. Allergy Drug Targets 2009; 8 (3): 176-181.

6. Canning B.J., Woo A., Mazzone S.B. Neuronal modulation of airway and vascular tone and their influence on nonspecific airways responsiveness in asthma. J. Allergy (Cairo) 2012; 2012: 108-149.

7. Национальная программа "Бронхиальная астма у детей. Стратегия лечения и профилактика". 4-е изд. М.: Оригинал-макет; 2012.

8. Вейн А.М., Соловьева А.Д., Колосова О.А. Вегетососудистая дистония. М.: Медицина; 1981.

9. Бабуни И.В., Мириджаян Э.М., Машаек Ю.А. Азбука анализа вариабельности сердечного ритма. Ставрополь; 2002.

10. Реброва О.Ю. Статистический анализ медицинских данных. Применение пакета прикладных программ Statistica. М.: Медиа Сфера; 2003.

11. Оганесян А.В., Восканян А.Г. Кортизол и бронхиальная астма. Аллергол. и иммунол. 2007; 8 (1): 129.

\section{Информация об авторах}

Лебеденко Александр Анатольевич - д. м. н., зав. кафедрой детских болезней № 2 ГБОУ ВПО "Ростовский государственный медицинский университет" Минздрава России; тел.: (863) 250-40-43; e-mail: leb.rost@rambler.ru

Семерник Ольга Евгеньевна - аспирант кафедры детских болезней № 2 ГБОУ ВПО "Ростовский государственный медицинский университет" Минздрава России; тел.: (918) 56-92-681; e-mail: semernick@mail.ru 